\title{
Capsule deletion via a $\lambda$-Red knockout system perturbs biofilm formation and fimbriae expres- sion in Klebsiella pneumoniae MGH 78578
}

Tzu-Wen Huang ${ }^{1,2}$, Irene Lam² ${ }^{2}$ Hwan-You Chang ${ }^{3}$, Shih-Feng Tsai ${ }^{1}$, Bernhard O Palsson ${ }^{2}$ and Pep Charusanti ${ }^{2^{*}}$

\begin{abstract}
Background: Klebsiella pneumoniae is a leading cause of hospital-acquired urinary tract infections and pneumonia worldwide, and is responsible for many cases of pyogenic liver abscess among diabetic patients in Asia. A defining characteristic of this pathogen is the presence of a thick, exterior capsule that has been reported to play a role in biofilm formation and to protect the organism from threats such antibiotics and host immune challenge.

Findings: We constructed two knockout mutants of K. pneumoniae to investigate how perturbations to capsule biosynthesis alter the cellular phenotype. In the first mutant, we deleted the entire gene cluster responsible for biosynthesis of the extracellular polysaccharide capsule. In the second mutant, we deleted the capsule export subsystem within this cluster. We find that both knockout mutants have lower amounts of capsule but produce greater amounts of biofilm. Moreover, one of the two mutants abolishes fimbriae expression as well.

Conclusions: These results are expected to provide insight into the interaction between capsule biosynthesis, biofilm formation, and fimbriae expression in this organism.
\end{abstract}

Keywords: Klebsiella pneumoniae, Capsule, Biofilm, Fimbriae, Expression profiling, Gene knockouts, Transmission electron microscopy, Infectious disease

\section{Findings}

\section{Introduction}

Klebsiella pneumoniae is a Gram-negative bacterium that is a member of the family Enterobacteriaceae and is closely related phylogenetically to the genera Escherichia, Salmonella, Shigella, and Yersinia. Medically, K. pneumoniae causes a wide range of diseases worldwide such pneumonia, urinary tract infections, and surgical wound infections that primarily afflict immunocompromised patients in hospital settings and long-term care facilities. The number of community-acquired infections caused by $K$. pneumoniae, however, has increased worldwide over the past several decades. For example, invasive forms of the disease characterized by bacteremic liver abscesses or endophthalmitis that are contracted in the community are endemic in Asia [1-3], especially in Taiwan [4-7], and reports of their

\footnotetext{
* Correspondence: pcharusanti@ucsd.edu

${ }^{2}$ Department of Bioengineering, University of California, San Diego La Jolla,

CA, 92093-0412 USA

Full list of author information is available at the end of the article
}

occurrence are now emerging in other parts of the world $[8,9]$. Infections caused by $K$. pneumoniae can be difficult to treat since many clinical isolates possess an extensive repertoire of antibiotic resistance genes. Ominously, some strains have now been isolated from different parts of the world that harbor New Delhi metallo- $\beta$-lactamase 1 (NDM-1) [10,11], a gene that confers resistance to carbapenem antibiotics, the last-line treatment option against most $K$. pneumoniae infections. Compounding the medical threat is the paucity of new antibiotics that are being developed against multi-drug resistant Gram-negative bacteria such as K. pneumoniae.

Despite its close relationship to other enterobacteria, one notable difference between $K$. pneumoniae and other members of this family is the presence of an extremely thick, hypermucoviscous, extracellular polysaccharide capsule that surrounds this bacterium. At least 77 distinct capsular serotypes have been reported to date [12], but virulent strains have been predominantly associated with the $\mathrm{K} 1$ and $\mathrm{K} 2$ serotypes, in particular K1 [12-15]. The genes responsible for biosynthesis of the 
capsule are normally located in a cluster that is 21 to $30 \mathrm{~kb}$ in length and comprise 16 to 25 ORFs [16]. The capsule is believed to be a major virulence determinant by protecting K. pneumoniae from phagocytosis [17-19] and destruction by antimicrobial peptides [20]. Furthermore, the capsule is thought to play a crucial role in biofilm formation, which allows the organism to colonize indwelling medical devices and better survive hostile conditions such as detergents aimed at removing the biofilms, since mutants of $K$. pneumoniae strain LM21 with disruptions in different genes involved in capsule biosynthesis produce less biofilm [21]. Consistent with these findings, a separate signature-tagged mutagenesis study also identified a mutation in ORF12 of the $K$. pneumoniae strain $43816 \mathrm{~K} 2$ capsule gene cluster that resulted in less biofilm formation [22]. On the other hand, a third study found that a non-encapsulated derivative of $\mathrm{K}$. pneumoniae strain $\mathrm{C} 105$ produced greater amounts of biofilm than the parental strain, and correlated this observation to the expression of type 1 fimbriae [23]. A fourth study found that type 3 fimbriae promoted biofilm formation in a strain that still possessed its capsule [24].

These findings in aggregate highlight the complex interaction between capsule biosynthesis, biofilm formation, and fimbriae expression. Against this backdrop, we investigated the relationship among encapsulation, biofilm formation, and fimbriae expression in K. pneumoniae strain MGH 78578. Significantly, we found that a non-encapsulated mutant produced larger amounts of biofilm as has been reported [23], but in contrast also found that no fimbriae was required for this phenotype.

\section{Materials and methods}

\section{Strains and primers}

Klebsiella pneumoniae strain MGH 78578 was purchased from ATCC. All other strains were generated as part of this study (Table 1). All primers for plasmid construction and gene knockouts can be found in Additional file 1.

\section{Growth media}

All experiments were conducted using bacteria grown in LB, low salt LB, or glucose M9 media. Low salt LB consisted of (per liter) $5 \mathrm{~g}$ yeast extract, $10 \mathrm{~g}$ tryptone, and $5 \mathrm{~g} \mathrm{NaCl}$, and was adjusted to $\mathrm{pH} 8.0$ with $\mathrm{NaOH}$. Glucose M9 was composed of the following chemicals (per liter): $6.8 \mathrm{~g} \mathrm{Na}_{2} \mathrm{HPO}_{4} ; 3 \mathrm{~g} \mathrm{KH}_{2} \mathrm{PO}_{4} ; 0.5 \mathrm{~g} \mathrm{NaCl} ; 1 \mathrm{~g}$ $\mathrm{NH}_{4} \mathrm{Cl} ; 100 \mu \mathrm{M} \mathrm{CaCl}_{2} ; 2 \mathrm{mM} \mathrm{MgSO}$; 2 g dextrose. Stock solutions of $\mathrm{CaCl}_{2}, \mathrm{MgSO}_{4}$, and dextrose were filter sterilized through Millipore ExpressPlus $0.22 \mu \mathrm{m}$ membranes (Millipore, Billerica, MA) and subsequently added individually to autoclaved solutions containing the first four chemicals. Hygromycin (Sigma-Aldrich,
Table 1 List of strains and plasmids used in this study

\begin{tabular}{|c|c|c|}
\hline $\begin{array}{l}\text { Strains/ } \\
\text { Plasmids }\end{array}$ & Description & Source \\
\hline \multicolumn{3}{|c|}{ K. pneumoniae strains } \\
\hline MGH 78578 & $\begin{array}{l}\text { Clinical isolate from a pneumonia } \\
\text { patient. Parental (wild-type) strain for } \\
\text { gene deletion. }\end{array}$ & ATCC \\
\hline$\Delta$ wzabc & $\begin{array}{l}\text { In-frame deletion of wzabc operon } \\
\text { (KPN_02510-KPN_02512) }\end{array}$ & This study \\
\hline$\Delta \mathrm{cps}$ & $\begin{array}{l}\text { In-frame deletion of capsule biosynthesis } \\
\text { cluster ranging from ugd (KPN_02493) to } \\
\text { galF (KPN_02515) }\end{array}$ & This study \\
\hline \multicolumn{3}{|c|}{ E. coli strains } \\
\hline Top10 & Competent cells for general cloning & $\begin{array}{l}\text { Life } \\
\text { Technologies }\end{array}$ \\
\hline \multicolumn{3}{|l|}{ Plasmids } \\
\hline pACBSR & $\begin{array}{l}\text { A p15A replicon plasmid containing an } \\
\text { arabinose-inducible } \lambda \text {-Red recombinase } \\
\text { and chloramphenicol resistance selection } \\
\text { marker }\end{array}$ & [25] \\
\hline pEXP5-CT & $\begin{array}{l}\text { General vector containing ampicillin } \\
\text { resistance used during sub-cloning to } \\
\text { make pACBSR-Hyg }\end{array}$ & $\begin{array}{l}\text { Life } \\
\text { Technologies }\end{array}$ \\
\hline $\begin{array}{l}\text { pSecTag/ } \\
\text { FRT/N5-His }\end{array}$ & $\begin{array}{l}\text { Vector containing a promoter-less } \\
\text { hygromycin resistance gene }\end{array}$ & $\begin{array}{l}\text { Life } \\
\text { Technologies }\end{array}$ \\
\hline $\begin{array}{l}\text { pEXP5-CT- } \\
\text { hyg }\end{array}$ & 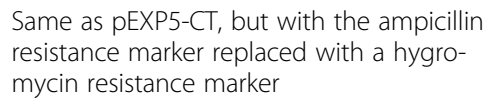 & This study \\
\hline pCP20 & $\begin{array}{l}\text { Plasmid bearing a heat-shock inducible } \\
\text { FLP recombinase }\end{array}$ & [26] \\
\hline plJ773 & $\begin{array}{l}\text { Template for amplification of the } \\
\text { apramycin resistance cassette }\end{array}$ & [27] \\
\hline $\begin{array}{l}\text { pACBSR- } \\
\text { Hyg }\end{array}$ & $\begin{array}{l}\text { Same as PACBSR, but with the } \\
\text { chloramphenicol resistance marker } \\
\text { replaced with a hygromycin resistance } \\
\text { marker }\end{array}$ & This study \\
\hline pFLP-Hyg & $\begin{array}{l}\text { Same as pCP20, but with the pSC101 } \\
\text { replicon and chloramphenicol resistance } \\
\text { marker of pCP20 replaced with the p15A } \\
\text { replicon and hygromycin resistance } \\
\text { marker from pACBSR-Hyg }\end{array}$ & This study \\
\hline
\end{tabular}

St. Louis, MO) and apramycin (Research Products International, Mt. Prospect, IL) were added to the media to final concentrations of $100 \mu \mathrm{g} / \mathrm{ml}$ and $50 \mu \mathrm{g} / \mathrm{ml}$, respectively, as necessary. Low salt LB and hygromycin are always used together; all other steps use standard LB.

\section{Construction of knockout mutants}

A detailed description of the knockout procedure and plasmid maps can be found in Additional file 2. A similar protocol was recently published [28].

\section{Capsule quantification}

The capsule surrounding K. pneumoniae MGH 78578 belongs to the $\mathrm{K} 52$ serotype, which has a hexasaccharide repeating unit composed of two rhamnose, one glucose, 


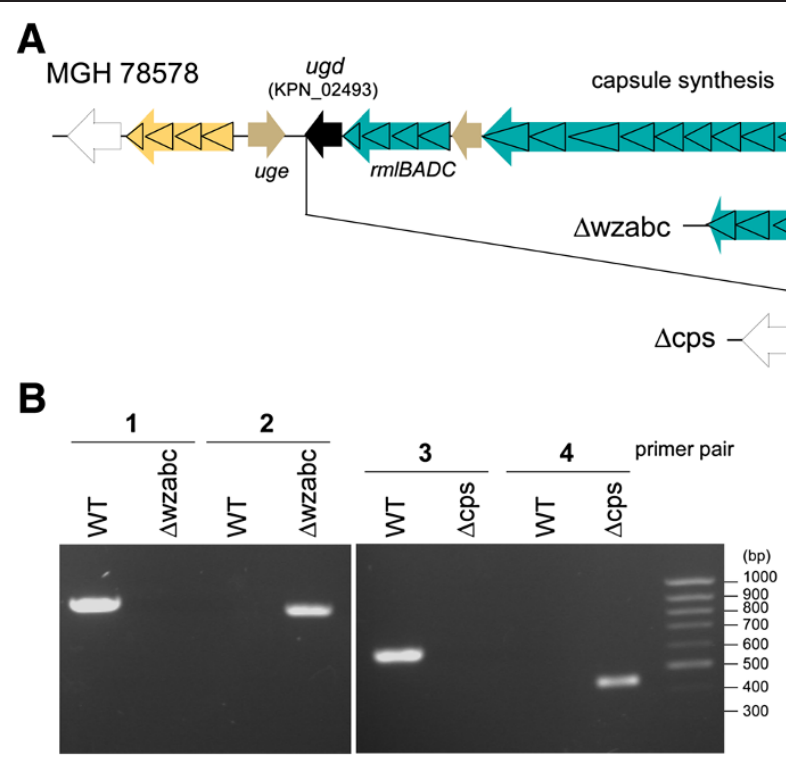

Figure 1 Construction of two capsule defective mutants, $\Delta$ cps and $\Delta$ wzabc. A. Genetic loci that were deleted in the two mutants $\Delta w z a b c$ and $\Delta \mathrm{cps}$. A portion of the capsule export system within the capsule biosynthesis cluster was deleted in $\Delta$ wzabc whereas the entire biosynthesis cluster was deleted in $\triangle \mathrm{cps}$. The deletions in both mutants left behind an $81 \mathrm{bp}$ scar region (red box). The triangles indicate the CDSs inside the gene clusters. B. Gel image confirming the deletions in both mutants. Two primer pairs ( 1 and 2 for $\Delta$ wzabc; 3 and 4 for $\Delta c p s$ ) were used to verify the deletions by PCR. The small arrows in part A denote the approximate binding location of the primers used to generate these amplicons. Pairs 1 and 3 were designed to amplify the $5^{\prime}$ and $3^{\prime}$ junctions of the wild-type sequence, respectively, while pairs 2 and 4 were designed such that either the forward or reverse primer from each pair bound inside the scar region. In this way, pairs 1 and 3 will produce a PCR amplicon if the wild-type sequence is still present, whereas pairs 2 and 4 amplify only if the correct target locus has been deleted. The amplicon sizes are: pair 1, 833 bp; pair 2, 741 bp; pair 3; 602 bp; pair 4, 428 bp.

one glucuronic acid, and two galactose sugars [29]. Measurements of the amount of capsule surrounding wildtype K. pneumoniae MGH 78578 and all the mutants were based on the protocol of Domenico, et al. [30].

\section{Transcriptome profiling}

For transcriptome profiling, a high-density oligonucleotide tiling array consisting of 379,528 50-mer probes spaced 30 bp apart across the whole $K$. pneumoniae MGH 78578 genome was custom-designed by NimbleGen (Roche). Total RNA from $\mathrm{OD}_{600} \sim 0.5$ cultures were hybridized to the arrays according to the protocol of Qiu, et al. [31]. The normalized probe level information was transformed into expression level data for each gene using the Genbank annotation for K. pneumoniae MGH 78578 (accession number PRJNA57619). Genes were deemed differentially expressed between the two mutants and the wild-type if there was a 2-fold or greater change and they had a p-value less than 0.05 . The expression profiling datasets of $K$. pneumoniae wild-type and capsule deletion mutant ( $\Delta \mathrm{cps})$ have been deposited in the Gene Expression Omnibus (GEO) database and assigned the accession number GSE40011. Three biological replicates of the wild-type, $\Delta \mathrm{cps}$, and $\Delta$ wzabc strains were used to generate the array data.

\section{Transmission electron microscopy imaging}

The samples were negatively stained with $1 \%$ aqueous uranyl acetate and examined on an FEI Tecnai G2 Sphera transmission electron microscope at $200 \mathrm{keV}$. Images were recorded on a Gatan Ultrascan UHS CCD camera.

\section{Results and discussion}

Deletion of the entire capsule biosynthesis cluster and the export subsystem leads to phenotypic defects in the two mutants

We developed a gene knockout procedure for $K$. pneumoniae that is based on the widely-used E. coli $\lambda$-Red recombinase system. The independent development of a similar protocol was recently reported [28]. The method developed here requires two selection markers, one (apramycin resistance) is used to replace the target gene and the other (hygromycin resistance) selects for two plasmids used at different times to mediate homologous recombination and excision of the apramycin resistance cassette.

We examined how different homology lengths affect transformation efficiency by deleting the same locus in K. pneumoniae using cassettes that contained 39-bp, 60bp, and 700-bp homology to the target region. This target region was the three genes $(w z a, w z b$, and $w z c)$ that 


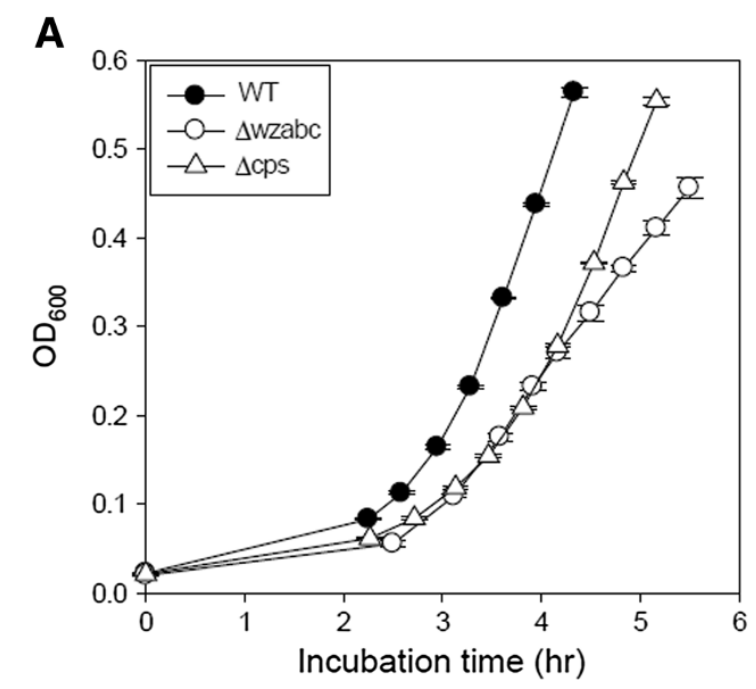

B

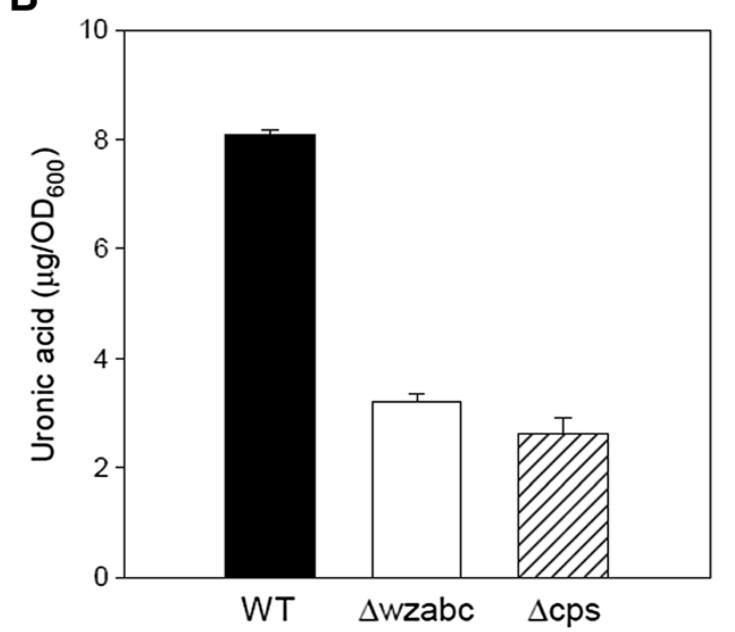

C

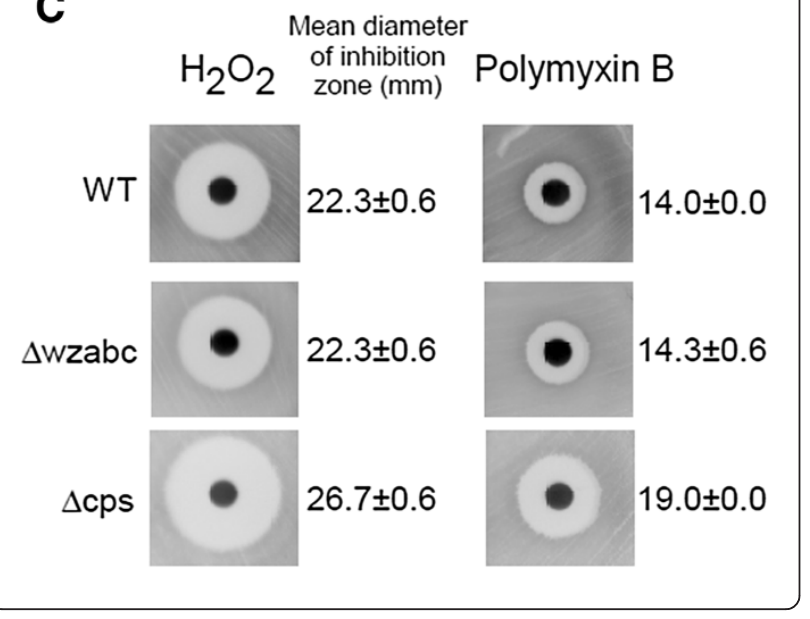

Figure 2 Phenotypic characterization of both capsule deletion mutants. A. Growth curves for the wild-type (WT), $\Delta$ wzabc, and $\Delta$ cps strains. B. Measurements of uronic acid content in the wild-type, $\Delta$ wzabc, and $\Delta c p s$ strains. Values were normalized by the optical densities of the samples when the measurements were made. $\boldsymbol{C}$. The susceptibility of the wild-type, $\Delta$ wzabc, and $\Delta$ cps strains to hydrogen peroxide (left) and polymyxin B (right). Error bars in all three panels denote the standard deviation of three biological replicates.

function in capsule export. A total of one microgram of each of the three PCR products was electroporated into the host. We recovered 26, 46, and 255 apramycinresistant transformants using the 39-bp, 60-bp, and 700bp homology lengths, resulting in transformation efficiencies of $1.3 \times 10^{-8}, 2.5 \times 10^{-8}$, and $1.1 \times 10^{-7}$, respectively. To confirm these mutant candidates, we next examined 24 colonies from each group by PCR. None of the 24 colonies from the 39-bp group was a correct knockout mutant, whereas two colonies from the 60-bp group and ten colonies from the 700-bp group were correct (data not shown). Although longer homology lengths resulted in higher transformation efficiency, these results implied that replacement cassettes containing 60-bp homology were sufficient to create knockout mutants. The construction of such cassettes requires DNA oligos that are only 80-85 nucleotides long, which can be readily purchased from commercial vendors. The use of knockout cassettes bearing longer homology arms would require an additional cloning step. For these reasons, we constructed all knockout mutants in this study using 60-bp homology.

We deployed our knockout protocol to investigate how the deletion of genes involved in biosynthesis of the thick, extracellular polysaccharide capsule surrounding K. pneumoniae perturbs the bacterium. We constructed two knockout mutants (Figure 1): the entire capsule biosynthesis cluster was deleted in one mutant, $\Delta$ cps, whereas three genes responsible for capsule export (the wza-b-c operon) were deleted in the other mutant, $\Delta$ wzabc (Table 1) $[32,33]$. Both deletions are markerfree, and we confirmed that the wild-type allele was completely absent in the two mutants by PCR and Sanger sequencing (Figure 1B).

The growth rates of the wild-type and $\Delta$ cps strains during batch culture in glucose M9 were $1.022 \pm 0.0028$ and 0.808 \pm 0.0057 (1/hour), respectively, indicating a statistically significant decrease in the growth rate $\left(P<5 \times 10^{-6}\right.$, Student's t-test) (Figure 2A). Growth rates were calculated from time-course $\mathrm{OD}_{600}$ measurements. The $\Delta$ wzabc mutant showed a biphasic growth pattern in which the growth rate during the first four hours was identical to that of the wildtype $(1.026 \pm 0.0481$ /hour $)$ but dropped to $0.49 \pm 0.010$ (1/hour) thereafter (Figure 2A). 
Table $\mathbf{2}$ List of the $\mathbf{2 0}$ genes most significantly up- and down-regulated in the $\Delta$ cps mutant relative to wild-type levels

\begin{tabular}{|c|c|c|c|c|c|}
\hline Locus & Gene product & $\begin{array}{l}\text { Expression level } \\
\text { (wild-type) }\end{array}$ & $\begin{array}{l}\text { Expression level } \\
(\Delta \text { cps })\end{array}$ & $p$-value & Fold change \\
\hline \multicolumn{6}{|c|}{ Up-regulated genes } \\
\hline KPN_00042 & Hypothetical & 9.00 & 13.38 & 0.0021 & 20.82 \\
\hline KPN_00321 & Hypothetical & 6.63 & 9.20 & 0.0007 & 5.92 \\
\hline KPN_01030 & Hypothetical & 8.15 & 10.65 & 0.0170 & 5.66 \\
\hline KPN_01107 & Hypothetical & 9.41 & 13.32 & 0.0021 & 15.03 \\
\hline KPN_01226 & Periplasmic protein & 10.59 & 13.27 & 0.0052 & 6.38 \\
\hline KPN_01279 & Lipoprotein, osmotically inducible & 11.03 & 13.96 & 0.0012 & 7.62 \\
\hline KPN_01568 & Hypothetical & 7.46 & 10.07 & 0.0085 & 6.10 \\
\hline KPN_01977 & Lysozyme inhibitor & 9.57 & 12.45 & 0.0007 & 7.34 \\
\hline KPN_02742 & Hypothetical & 8.95 & 11.38 & 0.0057 & 5.40 \\
\hline KPN_03160 & Hypothetical & 11.17 & 13.82 & 0.0028 & 6.30 \\
\hline KPN_04221 & Periplasmic repressor CpxP & 10.08 & 12.49 & 0.0044 & 5.32 \\
\hline KPN_04433 & Putative stress-response protein & 9.46 & 11.81 & 0.0083 & 5.09 \\
\hline KPN_04512 & N-glycosyl-transferase PgaC & 6.40 & 9.74 & 0.0003 & 10.13 \\
\hline KPN_04513 & Putative polysaccharide deacetylase & 6.38 & 9.79 & 0.0006 & 10.67 \\
\hline KPN_04514 ${ }^{a}$ & Outer membrane protein PgaA & 6.43 & 10.95 & 0.0002 & 22.95 \\
\hline KPN_04515 & Hypothetical & 6.56 & 12.30 & 0.0059 & 53.44 \\
\hline KPN_04516 ${ }^{a}$ & Hypothetical & 7.64 & 11.25 & 0.0010 & 12.21 \\
\hline KPN_04684 & Putative sulfate transporter & 8.78 & 11.67 & 0.0013 & 7.41 \\
\hline KPN_04685 & Putative carbonic anhydrase & 10.50 & 13.32 & 0.0049 & 7.02 \\
\hline KPN_04773 & Putative porin & 9.17 & 12.04 & 0.0026 & 7.31 \\
\hline \multicolumn{6}{|c|}{ Down-regulated genes } \\
\hline KPN_00464 & Copper exporting ATPase & 10.44 & 8.48 & 0.0024 & 0.26 \\
\hline KPN_00626 & methylthioribose kinase MtnK & 11.02 & 9.38 & 0.0052 & 0.32 \\
\hline KPN_00688 & tRNA-GIn-CTG & 13.17 & 11.34 & 0.0213 & 0.28 \\
\hline KPN_00689 & tRNA-GIn-CTG & 13.01 & 11.26 & 0.0287 & 0.30 \\
\hline KPN_01055 & tRNA-Ser-GGA & 13.00 & 11.11 & 0.0341 & 0.27 \\
\hline KPN_01427 & Hypothetical & 9.12 & 7.35 & 0.0040 & 0.29 \\
\hline KPN_02433 & tRNA-Asn-GTT & 15.01 & 12.52 & 0.0365 & 0.18 \\
\hline KPN_02448 & tRNA-Asn-GTT & 14.91 & 12.54 & 0.0246 & 0.19 \\
\hline KPN_02488 & dTDP-4-dehydrorhamnose 3,5-epimerase & 12.69 & 11.02 & 0.0032 & 0.31 \\
\hline KPN_02489 & dTDP-4-dehydrorhamnose reductase & 13.06 & 11.18 & 0.0035 & 0.27 \\
\hline KPN_02593 & Colicin I receptor & 14.38 & 12.83 & 0.0034 & 0.34 \\
\hline KPN_02746 & tRNA-Ala-GGC & 10.11 & 8.52 & 0.0257 & 0.33 \\
\hline KPN_02747 & tRNA-Ala-GGC & 10.36 & 8.87 & 0.0377 & 0.36 \\
\hline KPN_02920 & Bifunctional chorismate mutase/prephenate dehydratase & 11.74 & 10.24 & 0.0092 & 0.35 \\
\hline KPN_03277 & Putative fimbrial usher protein & 13.08 & 11.49 & 0.0024 & 0.33 \\
\hline KPN_03278 & Putative pili assembly chaperone & 13.66 & 12.05 & 0.0024 & 0.33 \\
\hline KPN_04263 & tRNA-Trp-CCA & 10.89 & 8.38 & 0.0088 & 0.18 \\
\hline KPN_04300 & tRNA-Pro-TGG & 9.93 & 8.11 & 0.0193 & 0.28 \\
\hline KPN_04425 & Maltoporin & 11.34 & 9.61 & 0.0051 & 0.30 \\
\hline KPN_04776 & Carbon starvation protein & 9.26 & 7.63 & 0.0043 & 0.32 \\
\hline
\end{tabular}

${ }^{a}$ Genes associated with the pga operon.

${ }^{b}$ Genes associated with the mrk type 3 fimbriae operon. 
The quantity of uronic acid that can be extracted from cells provides an indirect measure of the amount of extracellular capsule [34-37]. When compared to wildtype levels, the quantity of uronic acid in the $\Delta$ cps and $\Delta$ wzabc mutants declined to $0.29 \pm 0.17$ and $0.38 \pm$ 0.04 fold change, respectively $\left(P<7.5 \times 10^{-4}\right.$ for both, Student's t-test) (Figure 2B). As a negative control, we performed the same assay side-by-side using blank media only. Absorbance measurements for these control samples were consistently below the detection threshold of our spectrophotometer.

We next measured the sensitivity of the wild-type, $\Delta$ cps, and $\Delta$ wzabc strains to oxidative stress and the antimicrobial peptide polymyxin B since the absence of capsule was expected to increase sensitivity to these two stresses. Both measurements were carried out using a disc diffusion assay in which hydrogen peroxide or polymyxin $B$ was impregnated into the disc and then placed onto agar plates covered by a lawn of each strain. The diameter of the inhibition zone of the wild-type and $\triangle$ wzabc mutant to hydrogen peroxide was $22.3 \mathrm{~mm}$ in contrast to $26.7 \mathrm{~mm}$ for the $\Delta$ cps mutant $(P<0.001$, Student's t-test) (Figure 2C). Similarly, the antimicrobial peptide polymyxin $\mathrm{B}$ assay produced a diameter of $19.0 \mathrm{~mm}$ each time when three independent tests on $\Delta$ cps were performed, but only $14 \mathrm{~mm}$ on wild-type and $\Delta$ wzabc (Figure 2C).

\section{Expression profiling of the $\Delta c p s$ and $\Delta w z a b c$ deletion mutants reveals interplay between capsule biosynthesis and phenotypic defects}

The phenotypic changes we observed in the $\Delta$ cps capsule deletion mutant motivated us to examine gene expression differences between the $\Delta$ cps and $\Delta$ wzabc mutants versus the wild-type strain. Of 112 genes up-regulated more than two-fold (Table 2), those with the greatest fold increase belonged to the gene cluster KPN_04512 - KPN_04515, which is annotated as the pga operon that is responsible for synthesis of poly-beta-1,6-N-acetyl-D-glucosamine (PGA or poly-GlcNAc), a secreted, extracellular component of the biofilm matrix [38]. The transcription level of the pga operon was also slightly elevated in the $\Delta$ wzabc mutant (Additional file 3).

Eighty-nine genes were down-regulated more than twofold in the $\Delta$ cps mutant and fell within several groups: 17 plasmid-borne genes from pKPN3 and pKPN4, 13 metabolic genes, 11 tRNA genes, and eight genes associated with type 1 and type 3 fimbriae. Of the eight fimbriae-associated genes, five were located within the same cluster (KPN_03274 - KPN_03278) (Additional file 3). Genbank currently does not associate this set of genes with a specific type of fimbriae; however, each one is $100 \%$ homologous at the amino acid level to the $m r k J F D C B$ cluster from $K$. pneumoniae NTUH-2044 that encodes type 3 fimbriae. We therefore assume that this set of five genes encodes type 3 fimbriae in K. pneumoniae MGH 78578 as well. The other three (fimA, fimI, and fimC; KPN_03287 - KPN_03289) (Additional file 3) are located within a cluster whose gene product is annotated to be type 1 fimbriae.

\section{Fimbriae biosynthesis is abolished in $\Delta c p$ s but not $\Delta$ wzabc}

In lieu of standard RT-PCR, we interrogated the findings from expression analysis through a series of corresponding phenotypic assays. The down-regulation of genes encoding both type 1 (fim cluster) and type 3 (mrk cluster) fimbriae raised the possibility that fimbriation had declined in the two mutants. To investigate this possibility, we visualized the surface structure of the wild-type and the two knockout mutants using transmission electron microscopy (TEM). Fimbriae could be detected on the surface of the wild-type and $\Delta$ wzabc mutant but not on the $\Delta$ cps mutant (Figure 3).

\section{Up-regulation of the pga operon appears to be a more important factor in biofilm formation than down-regulation of the fimbriae-associated operons.}

Type 1 fimbriae has been previously linked to increased biofilm formation in a non-encapsulated $K$. pneumoniae mutant [23]. In our non-encapsulated $\Delta$ cps mutant, however, we observed twice as much biofilm relative to wild-type levels (Figure 4) but no fimbriae (Figure 3) when using a crystal violet assay to quantify the amount of biofilm [39]. These observations suggest that upregulation of the $p g a$ operon alone is sufficient to promote biofilm formation in non-encapsulated mutants; fimbriae are not needed. The $\Delta$ wzabc mutant produced even greater amounts of biofilm (four-fold increase) when compared to the wild-type (Figure 4), but the pga operon was overexpressed only 1.7-fold (Additional file 3). The continued presence of fimbriae suggests that, in this mutant, both the $p g a$ operon and fimbriae probably act synergistically to promote biofilm.

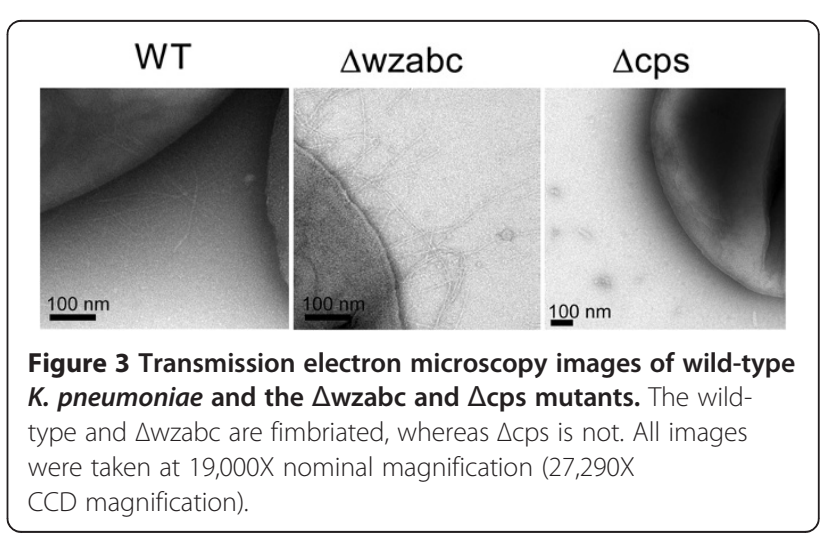




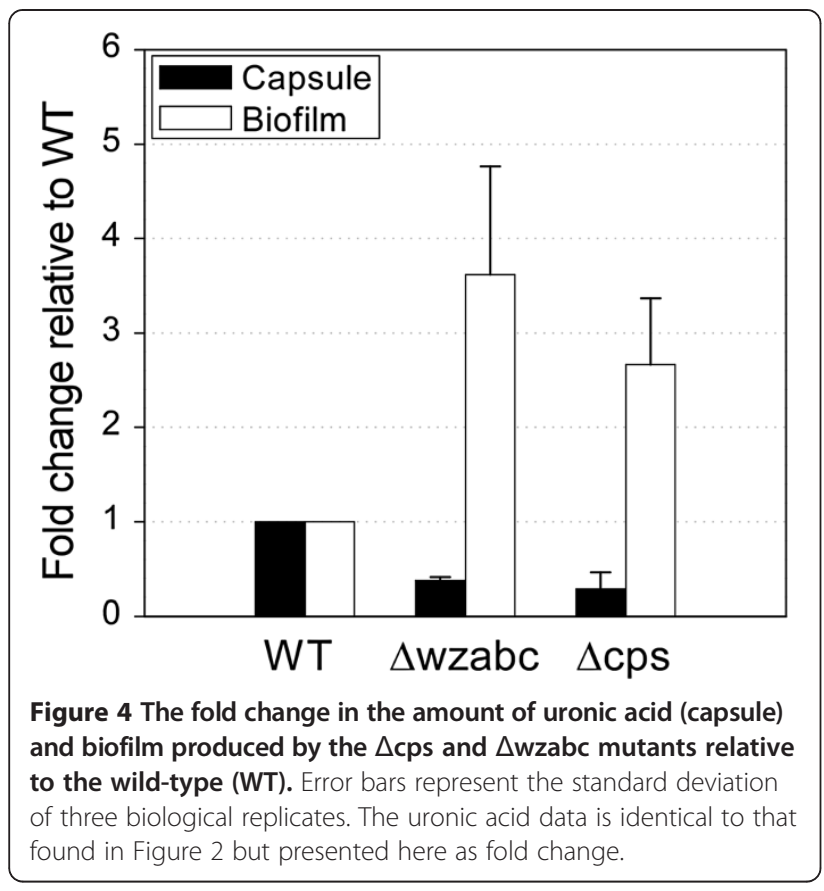

\section{Concluding remarks}

In this study, we observed a complex interplay among encapsulation, biofilm formation, and fimbriae expression in Klebsiella pneumoniae MGH 78578. This strain exhibited increased biofilm formation despite the absence of capsule, an effect likely stemming from strong up-regulation of the pga operon. In contrast, other strains with different deletions within the capsule biosynthesis cluster have been reported to produce less biofilm, not more $[21,22,40]$. It is not known, however, how expression levels of the pga operon might have changed in these other mutants. In addition, type 1 fimbriae have been reported to play an important role in biofilm formation in a non-encapsulated $K$. pneumoniae mutant [23], but no fimbriae was necessary for increased biofilm formation in the non-encapsulated mutant we generated (Figure 3). Taken together, these observations suggest that overlapping regulatory mechanisms likely act to regulate these three features in $K$. pneumoniae in a strain-specific manner.

\section{Additional files}

Additional file 1: All primers used in this study for plasmid construction and to generate and confirm the knockouts.

Additional file 2: Overview of the $\lambda$-Red based protocol to create gene knockouts in Klebsiella pneumoniae.

Additional file 3: The fold change of pgaABC and $m r k$ operons in $\Delta$ wzabc and $\Delta$ cps mutants.

\section{Competing interests}

The authors declare that they have no competing interests.
Authors' contributions

TWH, IL, and PC carried out the experiments. TWH, HYC, SFT, BOP, and PC designed the study. All authors participated in manuscript preparation. All authors have read and approved the final manuscript.

\section{Acknowledgements}

This study was funded from a grant from the National Health Research Institutes of Taiwan through PH-099-SP-10. We acknowledge the use of the UCSD Cryo-Electron Microscopy Facility which is supported by $\mathrm{NIH}$ grants to Dr. Timothy S. Baker and a gift from the Agouron Institute to UCSD. We thank Jay Sung-Joong Hong and Yu Qiu for helpful discussion on microarray experiments. We thank Nicole Fong and Valerie Khaw for technical assistance. We thank Dr. Frederick R. Blattner at the University of WisconsinMadison for kindly sharing the pACBSR plasmid and Dr. Carton W. Chen at National Yang-Ming University for kindly sharing the plJ773 plasmid.

\section{Author details}

${ }^{1}$ Institute of Molecular and Genomic Medicine, National Health Research Institutes, 350 Zhunan, Taiwan. ${ }^{2}$ Department of Bioengineering, University of California, San Diego La Jolla, CA, 92093-0412 USA. ${ }^{3}$ Institute of Molecular Medicine, National Tsing Hua University, 30013 Hsinchu, Taiwan.

Received: 1 August 2013 Accepted: 31 December 2013

Published: 8 January 2014

\section{References}

1. Chung DR, Lee SS, Lee HR, Kim HB, Choi HJ, Eom JS, Kim JS, Choi YH, Lee JS, Chung MH, et al: Emerging invasive liver abscess caused by $\mathrm{K} 1$ serotype Klebsiella pneumoniae in Korea. J Infection 2007, 54:578-583.

2. Kohayagawa Y, Nakao K, Ushita M, Niino N, Koshizaki M, Yamamori Y, Tokuyasu Y, Fukushima H: Pyogenic liver abscess caused by Klebsiella pneumoniae genetic serotype K1 in Japan. J Infect Chemother 2009, 15:248-251.

3. Siu LK, Fung CP, Chang FY, Lee N, Yeh KM, Koh TH, Ip M: Molecular typing and virulence analysis of serotype K1 Klebsiella pneumoniae strains isolated from liver abscess patients and stool samples from noninfectious subjects in Hong Kong, Singapore, and Taiwan. J Clin Microbiol 2011, 49:3761-3765.

4. Fang CT, Lai SY, Yi WC, Hsueh PR, Liu KL, Chang SC: Klebsiella pneumoniae genotype K1: an emerging pathogen that causes septic ocular or central nervous system complications from pyogenic liver abscess. Clin Infect Dis 2007, 45:284-293.

5. Fung CP, Chang FY, Lee SC, Hu BS, Kuo Bl, Liu CY, Ho M, Siu LK: A global emerging disease of Klebsiella pneumoniae liver abscess: is serotype K1 an important factor for complicated endophthalmitis? Gut 2002, 50:420-424.

6. Tsai FC, Huang YT, Chang LY, Wang JT: Pyogenic liver abscess as endemic disease, Taiwan. Emerg Infect Dis 2008, 14:1592-1600.

7. Wang JH, Liu YC, Lee SS, Yen MY, Chen YS, Wann SR, Lin HH: Primary liver abscess due to Klebsiella pneumoniae in Taiwan. Clin Infect Dis 1998, 26:1434-1438.

8. Abate G, Koh TH, Gardner M, Siu LK: Clinical and bacteriological characteristics of Klebsiella pneumoniae causing liver abscess with less frequently observed multi-locus sequences type, ST163, from Singapore and Missouri, US. J Microbiol Immunol 2012, 45:31-36.

9. Pope JV, Teich DL, Clardy P, McGillicuddy DC: Klebsiella pneumoniae liver abscess: an emerging problem in North America. J Emerg Med 2011, 41:e103-e105.

10. Kumarasamy KK, Toleman MA, Walsh TR, Bagaria J, Butt F, Balakrishnan R, Chaudhary U, Doumith M, Giske CG, Irfan S, et al: Emergence of a new antibiotic resistance mechanism in India, Pakistan, and the UK: a molecular, biological, and epidemiological study. Lancet Infect Dis 2010, 10:597-602.

11. Moellering RC Jr: NDM-1-a cause for worldwide concern. New Engl J Med 2010, 363:2377-2379.

12. Podschun $R, U$ Ilmann U: Klebsiella spp. as nosocomial pathogens: epidemiology, taxonomy, typing methods, and pathogenicity factors. Clin Microbiol Rev 1998, 11:589-603.

13. Fresno S, Jimenez N, Izquierdo L, Merino S, Corsaro MM, De Castro C, Parrilli M, Naldi T, Regue M, Tomas JM: The ionic interaction of Klebsiella 
pneumoniae K2 capsule and core lipopolysaccharide. Microbiology 2006, 152:1807-1818.

14. Mizuta K, Ohta M, Mori M, Hasegawa T, Nakashima I, Kato N: Virulence for mice of Klebsiella strains belonging to the 01 group: relationship to their capsular (K) types. Infect Immun 1983, 40:56-61.

15. Wu KM, Li LH, Yan JJ, Tsao N, Liao TL, Tsai HC, Fung CP, Chen HJ, Liu YM, Wang JT, et al: Genome sequencing and comparative analysis of Klebsiella pneumoniae NTUH-K2044, a strain causing liver abscess and meningitis. J Bacteriol 2009, 191:4492-4501.

16. Shu HY, Fung CP, Liu YM, Wu KM, Chen YT, Li LH, Liu TT, Kirby R, Tsai SF: Genetic diversity of capsular polysaccharide biosynthesis in Klebsiella pneumoniae clinical isolates. Microbiology 2009, 155:4170-4183.

17. Domenico P, Salo RJ, Cross AS, Cunha BA: Polysaccharide capsulemediated resistance to opsonophagocytosis in Klebsiella pneumoniae. Infect Immun 1994, 62:4495-4499.

18. Evrard B, Balestrino D, Dosgilbert A, Bouya-Gachancard JL, Charbonnel N, Forestier C, Tridon A: Roles of capsule and lipopolysaccharide $O$ antigen in interactions of human monocyte-derived dendritic cells and Klebsiella pneumoniae. Infect Immun 2010, 78:210-219.

19. Lawlor MS, Hsu J, Rick PD, Miller VL: Identification of Klebsiella pneumoniae virulence determinants using an intranasal infection model. Mol Microbiol 2005, 58:1054-1073.

20. Campos MA, Vargas MA, Regueiro V, Llompart CM, Alberti S, Bengoechea JA: Capsule polysaccharide mediates bacterial resistance to antimicrobial peptides. Infect Immun 2004, 72:7107-7114.

21. Balestrino D, Ghigo JM, Charbonnel N, Haagensen JA, Forestier C: The characterization of functions involved in the establishment and maturation of Klebsiella pneumoniae in vitro biofilm reveals dual roles for surface exopolysaccharides. Environ Microbiol 2008, 10:685-701.

22. Boddicker JD, Anderson RA, Jagnow J, Clegg S: Signature-tagged mutagenesis of Klebsiella pneumoniae to identify genes that influence biofilm formation on extracellular matrix material. Infect Immun 2006, 74:4590-4597

23. Schembri MA, Blom J, Krogfelt KA, Klemm P: Capsule and fimbria interaction in Klebsiella pneumoniae. Infect Immun 2005, 73:4626-4633.

24. Schroll C, Barken KB, Krogfelt KA, Struve C: Role of type 1 and type 3 fimbriae in Klebsiella pneumoniae biofilm formation. BMC Microbiol 2010, 10:179.

25. Herring CD, Glasner JD, Blattner FR: Gene replacement without selection: regulated suppression of amber mutations in Escherichia coli. Gene 2003, 311:153-163.

26. Cherepanov PP, Wackernagel W: Gene disruption in Escherichia coli: TcR and $\mathrm{KmR}$ cassettes with the option of Flp-catalyzed excision of the antibiotic-resistance determinant. Gene 1995, 158:9-14.

27. Gust B, Challis GL, Fowler K, Kieser T, Chater KF: PCR-targeted Streptomyces gene replacement identifies a protein domain needed for biosynthesis of the sesquiterpene soil odor geosmin. Proc Natl Acad Sci USA 2003, 100:1541-1546.

28. Wei $D$, Wang $M$, Shi J, Hao J: Red recombinase assisted gene replacement in Klebsiella pneumoniae. J Ind Microbiol Biotechnol 2012, 39:1219-1226.

29. Stenutz R, Erbing B, Widmalm G, Jansson PE, Nimmich W: The structure of the capsular polysaccharide from Klebsiella type 52, using the computerised approach CASPER and NMR spectroscopy. Carbohyd Res 1997, 302:79-84

30. Domenico P, Schwartz S, Cunha BA: Reduction of capsular polysaccharide production in Klebsiella pneumoniae by sodium salicylate. Infect Immun 1989, 57:3778-3782

31. Qiu Y, Cho BK, Park YS, Lovley D, Palsson BO, Zengler K: Structural and operational complexity of the Geobacter sulfurreducens genome. Genome Res 2010, 20:1304-1311.

32. Dong C, Beis K, Nesper J, Brunkan-Lamontagne AL, Clarke BR, Whitfield C, Naismith $\mathrm{JH}$ : Wza the translocon for E. coli capsular polysaccharides defines a new class of membrane protein. Nature 2006, 444:226-229.

33. Whitfield C: Biosynthesis and assembly of capsular polysaccharides in Escherichia coli. Annu Rev Biochem 2006, 75:39-68.

34. Dutton GG, Lim AV: Structural investigation of the capsular polysaccharide of Klebsiella serotype K35. Carbohyd Res 1985, 145:67-80.

35. Dutton GG, Paulin M: Structure of the capsular polysaccharide of Klebsiella serotype K53. Carbohyd Res 1980, 87:107-117.

36. Joseleau JP: Structural investigation of the capsular polysaccharide of Klebsiella serotype K 49. Carbohyd Res 1985, 142:85-92.
37. Nath K, Chakraborty AK: Studies of the primary structure of the capsular polysaccharide from Klebsiella serotype K15. Carbohyd Res 1987, 161:91-96.

38. Wang X, Preston JF 3rd, Romeo T: The pgaABCD locus of Escherichia coli promotes the synthesis of a polysaccharide adhesin required for biofilm formation. J Bacteriol 2004, 186:2724-2734.

39. Huang YJ, Liao HW, Wu CC, Peng HL: MrkF is a component of type 3 fimbriae in Klebsiella pneumoniae. Res Microbiol 2009, 160:71-79.

40. Wu MC, Lin TL, Hsieh PF, Yang HC, Wang JT: Isolation of genes involved in biofilm formation of a Klebsiella pneumoniae strain causing pyogenic liver abscess. PLoS One 2011, 6:e23500.

doi:10.1186/1756-0500-7-13

Cite this article as: Huang et al:: Capsule deletion via a $\lambda$-Red knockout system perturbs biofilm formation and fimbriae expression in Klebsiella pneumoniae MGH 78578. BMC Research Notes 2014 7:13.

\section{Submit your next manuscript to BioMed Central and take full advantage of:}

- Convenient online submission

- Thorough peer review

- No space constraints or color figure charges

- Immediate publication on acceptance

- Inclusion in PubMed, CAS, Scopus and Google Scholar

- Research which is freely available for redistribution 